\title{
Tuberculosis: an emerging zoonosis
}

\section{Larry Vogelnest}

Taronga Wildlife Hospital, Taronga Conservation Society Australia

Tuberculosis (TB) caused by Mycobacterium tuberculosis is primarily a disease of humans who are considered the primary reservoir host for this pathogen. It is an ancient disease, with descriptions dating back thousands of years. It is currently estimated that one-third of the global human population is infected, ${ }^{1}$ and TB accounts for millions of deaths annually.

\section{Mycobacterium tuberculosis in animals}

Humans have had a very close association with animals for millennia, utilising them for food, labour, transport, clothing, companionship, disability assistance, recreation, sport, religious and cultural icons, security, entertainment and research and in rescue, rehabilitation and conservation efforts. It is inevitable then that as a result of this close association, transmission of pathogens from humans to animals and vice versa will occur. M. tuberculosis infections have been reported in a wide range of animal species including: elephants, ${ }^{2-6}$ non-human primates, ${ }^{3,5,7}$ rhinoceroses, ${ }^{6}$ tapir, ${ }^{7}$ various non-domestic ungulates, ${ }^{6,7}$ seals, ${ }^{3,5}$ various non-domestic carnivores, ${ }^{5}$ $\operatorname{dogs},{ }^{8,9}$ cats, ${ }^{9}$ guinea pigs, ${ }^{10}$ rabbits, ${ }^{10}$ cattle $^{11}$ and birds. ${ }^{3,5,12}$ Susceptibility to infection with M. tuberculosis varies significantly between animal taxonomic groups, with species such as old world monkeys, lesser apes, elephants, hamsters and guinea pigs being highly susceptible; great apes, new world monkeys, canids, seals, tapir, rhinoceroses, pigs, rats and mice are moderately susceptible; and prosimians, felids, equids, ungulates, rabbits, birds and reptiles have low susceptibility. ${ }^{3}$ The susceptibility for many species is unknown. Animals are generally considered to acquire infection from humans with active $\mathrm{TB}$, however animal-to-animal transmission also occurs, including between different species. ${ }^{6}$

Historically, zoonotic TB has been associated with M. bovis, however the incidence has declined significantly with the control and eradication of M. bovis in many countries and the advent of the pasteurisation of milk. ${ }^{13}$ It is now emerging that animals are a potential source of M. tuberculosis infection for humans, and it is becoming an important occupational and public health concern. Although the relative incidence is low, there are now several reports of transmission of M. tuberculosis from animals to humans. ${ }^{5,6,9,14-17}$ In the majority of these cases infection occurred in humans that had a close and/or prolonged association with the infected animal/s, most commonly through occupational exposure.

\section{Risk factors for animal-to-human transmission}

Many of the risk factors identified for contracting TB from a human with active TB are equally applicable to acquiring infection from an animal. These include: the number of bacilli being actively shed; total time of exposure; droplet size; persistence of aerosols through insufficient ventilation; and immune status. ${ }^{13}$ Additional risks associated with working with animals include: proximity to an infected animal; aerosol-generating practices (such as the use of high pressure hosing when cleaning); conducting clinical veterinary procedures such as trunk washes in elephants; conducting necropsies on an infected animal; being an elephant trainer/keeper; and inconsistent or improper use of N95 masks when working with known or potentially infected animals. ${ }^{6}$ Generally, however, it is concluded that humans must be in close proximity to, and have more than incidental contact with, an infected animal to be at risk of infection. ${ }^{13,14}$

\section{Case studies of animal-to-human transmission}

A number of recent case studies provide examples of zoonotic M. tuberculosis infections. One report documents the infection of veterinary personnel during the clinical and pathological examination of a dog with unexpected disseminated TB. Contact investigation among the owners and veterinary personnel indicated that the index dog did not infect humans during its lifetime. However, all three pathologists performing the necropsy on the dog later returned positive results. Infection was most likely due to inhalation of aerosols created by using an electric saw to open the brain cavity. ${ }^{9}$

Tuberculosis caused by M. tuberculosis is emerging as an important disease of Asian elephants (Elephas maximus). ${ }^{2-6}$ There have been numerous reports of transmission of $M$. tuberculosis from elephants to humans. ${ }^{5,6,14-17}$ TB was diagnosed in two Asian elephants, three Rocky Mountain goats (Oreamnos americanus) and one black rhinoceros (Diceros bicornis) in the Los Angeles Zoo. Tuberculin skin test conversions were associated with working with the elephants and attending an elephant necropsy. ${ }^{6}$ Five employees working at an elephant refuge in Tennessee had tuberculin skin test conversions linked to the presence of an infected elephant at the refuge. Risk of conversion was increased for elephant caregivers and administrative personnel working 
in the barn housing the elephant or in offices connected to the barn. Indirect exposure to aerosolised organisms and delayed and inadequate infection control practices likely contributed to transmission. ${ }^{16}$ After the death of three elephants at an exotic animal farm in Illinois due to TB and the diagnosis in a fourth live elephant, 22 caregivers at the farm were screened for TB; 11 caregivers had positive tuberculin skin test reactions, one of whom was diagnosed with active TB. Genotyping demonstrated that the isolates from the four elephants and the caregiver with active TB were the same. ${ }^{15}$ After the diagnosis of TB in an Asian elephant and a chimpanzee (Pan troglodytes) in an Australian zoo, over 145 staff and volunteers were screened and completed a detailed questionnaire to assess exposure risk. There was no evidence of risk to people who did not work with the elephants. ${ }^{18,19}$

\section{Conclusion}

People should be aware of the risk of contracting TB from animals where there is a risk of animal exposure to M. tuberculosis, particularly with susceptible species and in regions of the world where the incidence of TB in the human population is high. Animal industries and professions (e.g. zoological institutions, the veterinary profession and wildlife rescue and rehabilitation centres) should have occupational health programs that include personnel education, adequate infection control practices, appropriate use of personal protective equipment, TB screening programs for susceptible species, regular screening of employees working with these species and pre-employment screening to establish baseline exposure for TB.

\section{Acknowledgment}

I would like to thank Nicola Stephens, Manager, Communicable Disease Epidemiology and Surveillance Section, Health Protection Branch, Department of Health, Victoria (work completed while at Communicable Diseases Branch, Health Protection NSW) for her assistance with the preparation of this paper.

\section{References}

1. World Health Organization. Tuberculosis factsheet. Available at: http://www.who.int/mediacentre/factsheets/fs104/en (Cited 25 June 2013).

2. Angkawanish T, Wajjwalku W, Sirimalaisuwan A, Mahasawangkul S, Kaewsakhorn T, Boonsri K et al. Mycobacterium tuberculosis infection of domesticated Asian Elephants, Thailand. Emerg Infect Dis 2010; 16: 1949-51. doi:10.3201/ eid1612.100862

3. Isaza R. Tuberculosis in all taxa. In: Fowler ME, Miller RE, editors. Zoo and wild animal medicine. 5th ed. Pennsylvania: WB Saunders Company; 2003. p. 689-96.

4. Mikota SK. Tuberculosis in elephants. In: Fowler ME, Miller RE, editors. Zoo and wild animal medicine. 6th ed. St. Louis: Saunders Elsevier; 2008. p. 355-64.
5. Montali RJ, Mikota SK, Cheng LI. Mycobacterium tuberculosis in zoo and wildlife species. Rev Sci Tech 2001; 20: 291-303.

6. Oh P, Granich R, Scott J, Sun B, Joseph M, Stringfield C et al. Human exposure following Mycobacterium tuberculosis infection of multiple animal species in a Metropolitan Zoo. Emerg Infect Dis 2002; 8: 1290-3. doi:10.3201/eid0811.020302

7. Michel AL, Venter L, Espie IW, Coetzee ML. Mycobacterium tuberculosis infections in eight species at the National Zoological Gardens of South Africa, 1991-2001. J Zoo Wildl Med 2003; 34(4): 364-70. doi:10.1638/02-063

8. Erwin PC, Bemis DA, McCombs SB, Sheeler LL, Himelright IM, Halford SK et al. Mycobacterium tuberculosis transmission from human to canine. Emerg Infect Dis 2004; 10(12): 2258-60. doi:10.3201/eid1012.040094

9. Posthaus H, Bodmer T, Alves L, Oevermann A, Schiller I, Rhodes SC et al. Accidental infection of veterinary personnel with Mycobacterium tuberculosis at necropsy: A case study. Vet Microbiol 2011; 149: 374-80. doi:10.1016/j.vetmic. 2010.11.027

10. Sakamoto K. The pathology of Mycobacterium tuberculosis infection. Vet Pathol 2012; 49(3): 423-39. doi:10.1177/ 0300985811429313

11. Fetene T, Kebede N, Alem G. Tuberculosis infection in animal and human populations in three districts of Western Gojam, Ethiopia. Zoonoses Public Health 2011; 58: 47-53. doi:10.1111/ j.1863-2378.2009.01265.x

12. Schmidt V, Schneider S, Schlomer J, Krautwald-Junghanns M, Richter E. Transmission of tuberculosis between men and pet birds: a case report. Avian Pathol 2008; 37(6): 589-92. doi:10.1080/03079450802428901

13. Maslow J. Tuberculosis and other mycobacteria as zoonoses. Proceedings American Association of Zoo Veterinarians. 1997; pp. 110-15.

14. Davis M. Mycobacterium tuberculosis risk for elephant handlers and veterinarians. Appl Occup Environ Hyg 2001; 16: 350-3. doi:10.1080/10473220120327

15. Michalak K, Austin C, Diesel S, Bacon MJ, Zimmerman P, Maslow JN. Mycobacterium tuberculosis infection as a zoonotic disease: transmission between humans and elephants. Emerg Infect Dis 1998; 4: 283-7. doi:10.3201/eid0402.980217

16. Murphree R, Warkentin JV, Dunn JR, Schaffner W, Jones TF. Elephant-to-human transmission of tuberculosis, 2009. Emerg Infect Dis 2011; 17(3): 366-71. doi:10.3201/eid1703.101668

17. Une Y, Mori T. Tuberculosis as a zoonosis from a veterinary perspective. Comp Immunol Microbiol Infect Dis 2007; 30: 41525. doi:10.1016/j.cimid.2007.05.002

18. Stephens N, Vogelnest L, Lowbridge C, Christensen A, Marks GB, Sintchenko V et al. Transmission of Mycobacterium tuberculosis from an Asian elephant (Elephas maximus) to a chimpanzee (Pan troglodytes) and humans in an Australian zoo. Epidemiol Infect 2013; 141(7): 1488-97.

19. Charlesworth KE, Vogelnest L, Stephens N, Marks GB. Diagnosis, investigation and management of tuberculosis at an Australian zoo. N S W Public Health Bull 2013; 24(1): 49. 